\title{
Language management and language work in a multilingual call center: An ethnographic case study
}

\author{
Johanna Woydack \\ Vienna University of Economics \& Business \\ johanna.woydack@wu.ac.at
}

\begin{abstract}
Drawing on long-term ethnography and interviews, I investigate language work and language management in a London multilingual call center. Using long-term participant ethnography and interviews, I examine how language issues are managed day to day, specifically in three previously overlooked areas: i) bow multilingual agents are recruited, ii) how agents are trained in language management, and iii) how their performance on the phone in multiple languages is evaluated and monitored. I reexamine the value of scripts, particularly in relation to knowledge management, and I challenge the idea that working language fluency on the phone is the principal skill required. Instead, I demonstrate that successful agents utilize a variety of skills learned with the help of scripts. I conclude that the term 'interactive professional' rather than 'language worker' better describes the skill set required by agents for this work.
\end{abstract}

Keywords: language work, language management 


\section{Introduction}

In the wake of post-industrialization, local governments have focused efforts on reintegrating the jobless into call center work. Such efforts are found in former industrial heartlands, including northeastern England, where companies have been lured by government aid and other financial incentives to revitalize the regions (Richardson and Belt 2001). They are also found in metropolitan centers such as London with high labor pools of recent underemployed graduates. However, these attempts frequently fail to maintain a stable workforce. Call centers incur high turnover rates, which indicates an underestimation of the skills and training required. Call centers aim to hire primarily from what they consider the bottom of the labor pool, with the ability to read and speak fluently from a script being the only qualification identified. However, often applicants are not low-skilled, but underemployed and, lacking other opportunities, accept call center work. Those recruited may not stay long if they are able to move upward in employment possibilities. Unfortunately, research on call centers is minimal and does not address why integration within the centers is not successful (Russell 2008), save a mention of the poor reputation of these centers among jobseekers (Lindsay and McQuaid 2004). In a review of a decade of call center research, Russell (2008) notes that HR researchers debate the lack of managerial attention and causes of attrition in call centers, such as achievement based remuneration. Moreover, as Russell explains, a lack of ethnographic and comparative research has fueled long standing debates in the management literature concerning the requisite skills and classifications of call centers, e.g., as low-skilled, semi-skilled or even knowledge work (Muller 1999).

The knowledge gap about call center work extends to linguistic studies. Although call center work has been broadly defined as 'language work' (see Heller 2010), specific skills have not been outlined. The assumption is that language fluency is the only skill required as this has been the only skill investigated (Presbitero 2017). By contrast, in the present study, I use ethnographic methods seldom applied to this arena to investigate the inner workings of a multilingual call center and explore how language issues are managed on a day-to-day basis, specifically, in three previously overlooked areas: i) the recruitment process for multilingual agents, ii) language management training, and iii) the evaluation and monitoring of phone performance in multiple languages. Examining these areas of language management offers better understanding of the necessary linguistic skills.

Previous research has critically focused on scripts (Cameron 2000a; Mirchandani 2004; Woydack and Rampton 2016), highlighting a perceived problem of deskilling and dehumanizing agents through the application 
of Tayloristic management practices. I open up a new area of research by reexamining the value of scripts in knowledge management and their importance in the day-to-day operations of a call center. In the researched call center, scripts are used to teach, assess, evaluate, and monitor fluency in another language. Scripts function as the key tool for the call center to operate multilingually. I challenge previous findings that calling scripts are problematic for agents and prevent learning and the idea that fluency in the working language is the principal skill required. Instead successful call center agents demonstrate a range of competencies in target languages and utilize a variety of skills, many learned with the help of scripts. They must be adept at both interacting with scripts and improvising responses while speaking to interlocutors. In turn the scripts themselves may scaffold workers' linguistic fluency. Given the range of skills needed the term 'interactive professional' rather than 'language worker' better describes the call center agent.

I build on Woydack (forthcoming) where I argue that agents' skills often remain invisible and illegible not just to industry outsiders but also to their managers because of both ideology and practice. These skills include emotional labor, procedural and substantive knowledge, and articulation work (cf. Hampson and Junor 2005). The latter refers to agents' management of the contradiction between quality and quantity that characterizes call center work. Woydack (forthcoming) finds that these skills remain invisible as they are oral and not recorded by software used to assess and monitor textual features of an agent's work. The same can be said about oral interactional skills, the focus of this paper. I make the point that low-paid work, in this case just above minimum wage, does not equal low-skilled, as skills are often invisible and go under appreciated in monetary terms in the wider economic and social environment.

To date, call center research on language work and language management has focused more on assessing language policy than on communication-related linguistic skills. For example, Alarcón \& Heyman (2013) stress when and how Spanish is used and who is considered/recruited as a Spanish speaker. My research instead focuses on concrete linguistic and interpersonal skills used by call center workers, in particular, working with scripts. I examine how traditionally rigid labels such as 'native speaker' and 'bilingual' take on fluid definitions in the workplace; for example, one can acquire 'native speaker' status merely through work experience at a call center.

If, as in previous research, call center work is treated as language work par excellence and language itself is manifested in all of its functions almost as an electrical current passing through a wire, the true workings inside a call center are 
oversimplified and distorted. The sections below break down many day-to-day practices 'on the ground' in call centers, including activities vital to multilingual tasks, to give greater nuance and texture in understanding both the managerial and agents' work processes. I address recruitment, assessment of linguistic proficiency, and evaluation of on-call performance.

\section{Language workers, scripts, and language management in the call center literature}

Russell (2008) divides call center literature in management studies into two types: one concerned with classification and systems of management control, and the other focused on issues such as employee voice, technology change, and emotional labor with call centers acting as a metaphor for wider social changes. In general, however, he notes that there is some agreement among researchers that no two call centers are exactly the same (2004), they are complex organizations in which features such as teamwork, levels of pay, training, and education and the amount of discretion that agents have over their work may all vary significantly (Batt and Moynihan 2002). Despite these acknowledged differences, researchers have suggested that they have some commonalities. With regards to classification, Taylor and Bain's seminal research (1999; 2001; 2004) suggests call centers involve extensive use of digital technology, deliberately limiting worker autonomy through monitoring and scripting. This is cost-efficient and represents the Taylorization of white-collar information work, with agents meeting continuous targets similar to a production line. Taylor and Bain consider the application of Tayloristic management practices to result in deskilling of agents, while other researchers argue that agents gain new skills, making call center work semiskilled and incomparable to assembly lines. Although skills are not focused on in detail, it is noted that call center workers, unlike counterparts in factories, exercise control over aspects of their jobs such as time investment and conversing with co-workers or with interlocutors on the phone.

The approach to labor processes pursued by Taylor and Bain focuses on using management and technology to instill and maintain discipline in a newly created white collar proletariat; in contrast, another line of research, taking a neo-Weberian perspective (e.g. Korczynski 2001; Frenkel 1999), describes a more positive scenario. In this approach, information is used by management for coaching purposes rather than solely for discipline, and agents are knowledge workers who struggle with the quality-quantity contradiction at the heart of call center work. Houlihan (2002) suggests that front-line managers function as 
mediators alleviating and renegotiating tensions that agent's experience in their work. Managing these tensions has been theorized as articulation work. HRstudies have further found that these front-line managers offer games and social activities to alleviate the tension and stress that accompany call center work. It is not clear to HR researchers why more high-commitment management practices are not implemented to lower high attrition rates, but they assume a managerial lack of interest, given a highly elastic labor market for continuous recruitment. Russell (2008) concludes that call center work and management remain undertheorized and under researched. Importantly, extant research does not reveal much about the linguistic aspect of call center work.

While call center literature in management studies stems mostly from the 1990 s, call centers began to penetrate the public consciousness and to generate interest among linguists as an area for 'language work' research (Heller 2003, 2010; Duchêne and Heller 2012) around the turn of the millennium. ${ }^{1}$ The notion of 'language work' as Duchêne describes, is the "activity in many areas such as call centers where language is central not just as the process but as the product of work" (Duchêne and Heller 2012, 13).

Underlying most of the literature are two main assumptions or 'language ideologies' (e.g., Woolard 1998), understood here to be beliefs about how language functions in the workplace. The first is the assumption that fluency in the working language on the phone is a pre-requisite for call center work. While agents in onshore call centers in the West are assumed to be L1 (first language) speakers and thus fluent in the language they call in, those offshore (in developing countries) are generally believed to be L2 (second language) speakers, who must meet strict requirements and undergo rigorous training before they are allowed to work (Lockwood 2012) ${ }^{2}$. Secondly, researchers believe that standardization through scripts is a negative feature of call center work, creating deskilled, replaceable robots within a Neo-Taylorist assembly line. In this view the communication skills of agents are "a selling point" (Duchêne 2009, 30) leading to language regulation and standardization through calling scripts and monitoring. Boutet (2012) writes that "beyond being a language profession, work in call centers today is mainly characterized by an extreme standardization of vocal productions: standardized voices, formatted discourses, and reduction of linguistic variability" $(2012,217)$.

1 Most of the previous debate surrounding language workers has focused on whether language is a commodity (McGill 2013; Block 2013). This paper does not weigh in on this debate, which is pinned to philosophical questions about what a commodity is. Instead it seeks a different approach by looking at the ethnographic data directly to find out what constitutes language work.

2 In fact, there have been several studies by Lockwood on how English is assessed as a second language in offshore call centers, but the focus of this paper is on onshore call centers. 
Some authors argue that the verbatim reading of scripts required on the phone removes linguistic agency (e.g., Roy 2003, 282), turning script-users into the mouthpieces of companies (e.g., Cameron 2008, 144, 2000b, 324), 'phone clones' (Mirchandani 2004, 359-62, 2012, 86-87), and robotic machines. Many have argued that scripting ultimately deskills agents and no learning can take place when working to a script (Cameron 2000a, 91-125; Ritzer 1998, 64). As a result, standardization, especially in calling scripts, is often the focus of interdisciplinary call center literature (see for a more detailed discussion Woydack \& Rampton 2016). Moreover, according to Heller and Bell $(2012,167)$, there is a contradiction at the heart of linguistic management policies in the new economy because on the one hand they attach value to the authenticity and legitimacy of fluent speakers, while on the other hand they pursue greater Neo-Taylorist standardization through scripts. This reflects the contradiction mentioned earlier in the management literature on quality vs. quantity; a contradiction that pervades call center work.

In the literature, three studies stand out for their focus on language policy in multilingual call centers: Duchêne (2009), Roy (2003), and Alarcón \& Heyman (2013). These three focus on language management, practices, and beliefs about languages for making calls. They address how a formal abstraction of a language, such as Spanish or English, is used, managed, and viewed by agents and managers in bilingual/multilingual call centers. These are, as far as I am aware, the only studies of bilingual/multilingual call centers. Two of them are ethnographic: Duchêne conducted ten days of fieldwork and Roy six months.

Two main themes emerge within this research. The first is the role of scripts in the language standardization for call center agents and their negative impact. All three studies emphasize that call centers are characterized by NeoTaylorist standardization. They stress the negative impact that standardization and especially scripting has on agents because of the way they devalue agents' language skills. Roy, drawing on fieldwork in Ontario, Canada, describes how agents who consider themselves French/English bilinguals undergo a French language test, and many of them do not pass as they do not speak the standard variety of French desired by the call center but are still hired as they represent cheap bilingual labor and no other French speakers are available to work in those call centers. Those that pass still follow a script to ensure they sound professional and to please their employer. Equally, Alarcón \& Heyman (2013) describe bilingual call centers on the U.S. border with Mexico where agents do not get additional remuneration for their Spanish language skills; rather, their ability to speak Spanish is treated as a "free attribute". The authors are critical of the 
usage of scripts and see them as contributing to the exploitation of agents. They conclude that "Neo-Taylorist management practices typical of mass market call centers" are the culprit (Alarcón and Heyman 2013, 18). Key features of these centers are control, high turnover of personnel, and little perceived need for training, turning agents into low wage workers whose knowledge of Spanish can be exploited essentially for free (Alarcón and Heyman 2013).

The second main theme in this literature centers on legitimacy and authenticity. Roy $(2003,269)$ and Alarcón \& Heyman note that the labor market in the new economy redefines who is bilingual (Alarcón and Heyman 2013 , 2). They find that optimization of work is more important than linguistic precision, meaning that agents are often asked to take calls in Spanish or in English or code switch although they might not be fully fluent. The call centers also do not dismiss certain accents or a lack of accents as illegitimate $(2013,13)$. The authors observe: "Management as much as employees recognize that some of these workers do not have sufficient formal competence in Spanish and have a low ability to communicate in English" $(2013,14)$. They note:

[...] [the first screening of the calls] can change flexibly between English and Spanish according to the instructions that appear on the monitor with each entering call, but always following a script in each of the languages. At immediately higher levels [e.g., when calls are transferred to technical support after first screening] not all of the service information is in the form of a script, although normally it is for the most recurrent topics. For this, the employee translates freely from/into English, producing a continual code-switching without a pre-established guide, flowing between the two interlocutors, while consulting an order screen, the telephone menu, or a television screen. $(2013,13)$

Issues of legitimacy and authenticity are viewed differently by the different parties. Management in an El Paso call center and its recruiters struggle with language assessment because according to a local development officer, they "do not have a very good idea what is Spanish" $(2013,17)$. Agents' Spanish is not properly assessed and linguistic training for agents does not exist $(2013,17)$. On the other hand, Mexican agents, the authors note, consider legitimacy differently and look down on their working-class Mexican-American colleagues. Mexican agents resent having to take Spanish language tests in the United States to prove their Spanish ability despite having Mexican credentials. The authors conclude that legitimacy and authenticity in these bilingual call centers is achieved through ethnic affiliation, i.e. being Mexican or Mexican-American, and fluency in Spanish is ratified through a business or (U.S.) public authority (e.g., a state court). 
In a Swiss call center case described by Duchêne (2009), ethnic affiliation - in this case being considered a native speaker' - indexes legitimacy and authenticity. Thus, the customer who is calling selects through an automatic service (2009, 40) the language in which he would like to conduct the call. Computer software detects the language spoken, then decides which employee will speak. Duchêne writes that the underlying assumption under which the program operates is that a native speaker should always be available to maximize efficiency. He notes that the call center manages a hierarchy of language skills, identifying preferences for particular countries of origin for their workers: French people are preferred to speak with native French speakers while Germans are chosen to speak with German speakers. Although Duchêne's case study provides insight into the management of call centers, he accepts that agents are fluent in the language they take calls in. Furthermore, he does not explain how language proficiency is assessed, how workers are recruited, or how notions such as bilingual or native are understood. Finally, it is unclear how success is measured. He leaves unanswered whether it is a matter of how many conversations agents complete or the quality of those conversations. In the third ethnographic study of bilingual call centers in Ontario Canada, Roy (2003) finds that the Francophone agents' language skills are not deemed adequate and for this reason they are given scripts. In Roy's view, the fact that Francophone Canadian agents have to follow scripts even though they are fluent French speakers and have to pass a standardized French test, not only devalues the particular variety of French they speak, but also questions their legitimacy.

In summary, these authors writing from a linguistic perspective look at 'language policies' toward specific languages rather than examining details of how linguistic ability is assessed, taught, and monitored in the daily practice of call center work. Understanding these everyday processes can expand the definition of 'language work', and provide a better sense of whether the term bears any relevance to the real world demands of this growing sector of the new economy.

\section{The study, methodology and field site}

The data in this paper were collected as part of an ethnography of a multilingual call center. Methods used include participant-observation and interviews with over 70 members of staff (call center or floor managers, team leaders, agents, and former agents). I worked at the call center for four years, on the phone and as a trainer. I conducted participant observation for three years as part of my $\mathrm{PhD}$. The management agreed to the research and I informed new agents of my research. Interviews were conducted outside the call center and included consent 
forms and information sheets ratified by King's College ethics procedures, ensuring informed consent and guaranteeing anonymity. Interview questions focused on topics ranging from agents' backgrounds to their beliefs about call center work, scripts, and monitoring. After interviews were transcribed, they were thematically coded on NVivo and crosschecked with the three questions examined as part of this paper (see introduction). I did not interview the corporate management, who take little part in the day-to-day running of the center and who are located on a different floor from the call center, call floor, managers and agents. Corporate managers are more involved with talking to clients than in calling activities. However, I did attend meetings with them and took notes on which I draw in this paper. The particular call center that I researched, which I shall refer to as 'CallCity', is located in London and advertises calling on behalf of external clients in any language requested. CallCity is an outbound IT call center that only conducts business-to-business calls. There are around 60 seats for agents to work from, with the exact number employed at any time varying depending on demand. The call center offers many services including customer service, surveys, and marketing for external clients. Comparing with data released by the Department of Trade and Industry (DTI 2004) on call centers in the UK, CallCity is typical of call centers in London and the South East of England.

The calls for standardized low-end campaigns were predominately unsolicited, marketing calls which involved the interlocutor on the phone agreeing to receive an email with a free report in exchange for some contact information and a call back from the external client. Conversely, the high-end campaigns involved requested call backs and were more of a service nature. While inbound call centers have found it harder to rely on scripts for handling inbound calls (Sallaz 2015), outbound call centers like CallCity are more routinized and commonly use scripts.

At the time of thefieldwork, there were six call center managers and five team leaders for sixty or so agents (Woydack 2019). All employees of the call center except for the call center managers were on temporary contracts and it was not possible for team leaders to be promoted or receive permanent contracts. Agents' workdays were regulated depending on which time zones they were calling and the time of the business quarter. In many ways, CallCity appears to meet the criteria of a low-skilled, low-paid, highly Taylorized call center with monitoring, and scripts. The turnover of staff was high, with 20 new agents starting work every week. Management did not address high attrition rates with high commitment strategies. Although measures such as incentivized remuneration packages were in place if agents met their numerical targets, call center managers openly 
expressed that London's elastic job market meant that continuous recruitment of underemployed, skilled graduates, was not a problem. At the same time the elastic job market also meant that agents kept leaving CallCity as they found permanent jobs in their field of expertise.

Officially, the only requirement for employment for agents was to be a (native) speaker of another language. Clients are assured that only native speakers of the target market will place calls. However, as part of my fieldwork, I observed this was often not the case and in interviews agents praised the call center for being a "free language course":

Extract 1

One of the greatest things about this job is that it gave me the opportunity to call in English as well, and I know that my first calls weren't so good. I really think that in the month and a half I improve a lot in English. Now I feel a lot more confident when I call in English. (...) it's like to take a language course in which you are being paid instead of paying. (Pablo, agent) (Source: Woydack 2016)

Pablo's case raises several questions: i) on what criteria do agents like Pablo get recruited if they are neither native or fluent?; ii) how are they trained so that they can work on the phone despite their non-fluency in the working language(s)?; and iii) how are they assessed? I address these questions, using Spolsky's position on language practices as "observable [linguistic] behaviors by participants" $(2009,4)$ and the choices that they make. In doing so, I explore how 'language' is managed, practiced, and conceptualized, not in the abstract of official language policies but in 'language work'.

\section{The multilingual call center and its recruitment practices}

The call center faces several recruitment challenges. The first is to hire preferably 'native speakers'. Officially, there is a 'native speaker' only policy, stated in communication with clients and in brochures to prospective clients, although the notion of 'native speaker' is not defined by the call center or clients. Certain languages are more in demand than others, and finding speakers willing to work in a call center is difficult. The second challenge is to manage the chronic shortage of multilingual speakers. Ideally, an agent would speak all the languages required per target country, but this is seldom realized. With continuously high targets, for example, in the Netherlands and Dutch (Flemish)-speaking regions in Belgium, the call center in particular values Dutch (Flemish) speakers. 
Switzerland is the multilingual other country targeted by the call center. The fact that Switzerland and Belgium are both officially multilingual complicates the calling and recruitment process. The call center, which on average deals in 20 different languages, struggles to assess the language proficiency of all its employees. It often resolves these issues by working with what is known as a 'language agency'.

\section{Recruiting through a language agency}

With approximately 60 per cent of agents coming from a language agency, there is a good chance that a new agent will have been recruited externally. In this case, the call center pays $£ 15$ an hour on top of normal wages, thus making external agency hires costly. At the same time, the call center constantly needs foreign language speakers at short notice. Despite the cost involved, it is often easiest to rely on language agencies with armies of foreign language speakers who are passed around London's call centers. An agency will have asked applicants to complete written and spoken language tests to ensure they are intermediate/ fluent/native in the language(s) claimed. The call center does not have the same capabilities to carry out language tests.

Because of their cost, agency hires are the first to be let go if there is insufficient work, unless they perform exceptionally well. Agency-hired callers increase the cost of a campaign, so these agents need to meet higher calling targets. Whether an agent has been employed externally or directly is more closely related to his/ her profitability to the organization than to his/her individual background or skills. There is, however, a final means for a call center to circumvent shortages and expensive language agencies.

\section{Recruiting directly online and upskilling speakers with a calling script}

In a job advertisement, call center management distinguishes between work experience (e.g., IT or call center) and language knowledge requirements, with the former being desirable but the latter being mandatory. Thus, according to advertisements, the only requirement agents need to fulfill is specific knowledge of a European language. Noticeably, the level of proficiency applicants must possess is not addressed. Nor does an advertisement specify whether new agents merely need oral skills in a specific language or should be literate as well.

Most agents hired directly are recruited as 'native speakers'. Many have beginner or intermediate knowledge of another language(s), besides the one 
they were originally hired for, which the managers are aware of from CVs. If the opportunity arises, for instance, at the end of the quarter or when it would otherwise be too expensive to hire new people, agents may be then asked to call in the other language they speak as 'semi-fluent' speakers with the aid of a translated script.

Agents often agree to this for several reasons. The majority are highly skilled, but underemployed thus willing to adjust their work skills to call center employment until better opportunities arise. One group are recent post-graduates looking for their first professional job. Others have recently immigrated to the UK where they find that their previous professional qualifications and work experience are not recognized. Their limited English skills might also be a hindrance to finding work in their desired career. As mentioned, many informants explained that the call center helped them improve their English (and other language skills). Jackie, a native Mandarin speaker, joined the call center with low English skills, like Pablo (Extract 1). Since the call center has very few campaigns in Mandarin, the position presented an opportunity for her to improve and practice her English. In retrospect, she concluded "I improved a lot on my oral English, just because of the job, and I think that one year it has [been] very valuable for me, yes".

Agents like Pablo and Jackie are not allowed to call on all campaigns. Out of the different kinds of campaigns, low-end ones, so called 'engagement campaigns,' are most standardized and script-based and consequently semi-fluent speakers like Pablo and Jackie are able to participate. Conversely, on high-end campaigns, agents are expected to have in-depth technical conversations, improvise and talk off script, thus semi-fluent speakers are excluded. On certain high-end campaigns, however, exceptions are made if the call center cannot find a 'native' speaker, but the client cannot know this.

Overall, corporate management desires 'native speakers' only. The lower call center or call floor management itself is more flexible though, advocating preferential native speaker recruitment if possible, but not always. Linguistic practices on the ground reflect gearing toward profitability, which may preempt the 'native' policy. Both agents and call center floor managers believe that agents can learn and succeed on the phone independent of their current language level. Otherwise, they would not be asked to call. However, call center managers do have faith in labels such as 'native' as a marker of proficiency. 


\section{The difficulty of labeling and assessing linguistic proficiency}

We have seen that call centers desire native speakers, but will hire agents who are less than fluent and can only call with the aid of scripts. How are traditional labels such as 'native speaker' and 'bilingual' used and defined? How is proficiency assessed? Coulmas defines'nativeness' as: "speakers [who] are citizens of the nation state where the target language is the national language and [for whom] the target language was acquired in early infancy in conjunction with primary socialization in a monolingual environment" (cf. Coulmas 1981,4) cited in Fraurud and Boyd 2011). Based on my participant observation, anyone is considered fluent who has lived in or has a passport from a country where a target language is spoken as an official language (e+g., English in India). 'Native' is also often used as a synonym for 'fluent.' Call center managers seldom know more than one of the languages used for calling (such as Spanish, German, French) and so cannot assess factors beyond nationality or residence for language proficiency.

As noted above, call centers rely heavily on scripts. Their use resolves problems in determining a standard of fluency that managers are ill-equipped to assess and provides a benchmark for performance. Given an original script handed down from corporate management, call floor leaders assign those they consider to be 'native' to translate the document into their native language for callers.

During my fieldwork, I have noticed a general assumption on behalf of the call center management that 'native' speakers should be able to do anything, as if they had superpowers. Pennycook noted the common perception of native speakers as having "a high level of proficiency in all domains" (Pennycook 1994, 176) and that because of their "complete and possibly innate competence" (Pennycook 1994, 175), they are well-received by the people they contact over the phone. Furthermore, call center management expects 'native' speakers to easily translate scripts into their native language, despite the 'natives' saying to me they are not always familiar with select domains of their L1, such as technical terminology.

Agents such as Karin, a German caller who in German, discussed the difficulty in adapting scripts written in one language into a different culture. The importance of knowing cultural norms of the target market when translating a script is a challenge:

\section{Extract 2}

You have to be so careful when you translate scripts. Every market is different. When you call Germany, you can't just say "Hi” address them by their first name 
and say "how are you today"? as you do in Britain. You need to be formal, use "Sie" and the correct title [... ]. (Karin, agent)

Call center management is aware of this problem and provides some tips to agents in the form of handouts for specific countries. In this way, it is thought that sociolinguistic competence can be standardized and made accessible through training sheets. Several agents further pointed out that scripts provide examples of correct grammar which helped them improve their grasp of a language. For instance, Nicole said the following about her German:

\section{Extract 3}

It [the script] has been very helpful [...] I understand a lot of German but I can't always get the grammar right. [...] I'm very talkative [...] but... make loads of mistakes $[\ldots]$ I think the script has been very helpful for me [...]. [...] I'm improving my German $[\ldots]$. (Nicole, agent)

Agents such as Nicole reported that when they applied for jobs outside the call center industry and submitted a CV noting their calling languages, they were considered 'native' and 'fluent' speakers. In my sample, at least twenty people had such experiences. Assumptions by external recruiters that call center agents are fluent in calling languages works in their favor.

Finally, in interviews with team leaders and agents, I asked whether nativeness would make a difference in their performance. According to them, this is not the key to success:

Extract 4

I have seen callers who barely spoke any English to be very successful [...] To be honest, from practical experience, I think being a native speaker or even being fluent is not important [to be a good caller]. (Olivia, former team leader)

When it comes to linguistic practices on the ground, call center managers and team leaders disregard corporate management's notion that native speakers are the best callers. They believe that neither fluency nor nativeness is a guarantee for success. These terms are used flexibly on the call center floor. So, if fluency and language proficiency are not key, how are success and failure assessed?

\section{Monitoring and assessing success and failure}

Having discussed the multilingual side of call center work, I explore the interactive skills considered more important than fluency for call center agents. I first examine how agents are trained. For most, training consists of half a day. During training agents become acquainted with a 'master script'. Subsequent monitoring and 
evaluation of agents on the phone and the corresponding framework on which this is based are derived from the master script, a typed and printed document provided by the client. During training, the entire master script is read aloud to agents, and team leaders make clear key points to be stressed on the phone. These are i) reasons for the call, ii) whom they are targeting, and iii) benefits (of the material they are asking to send out to the people they call).

How do team leaders cover this material? The first step is to make general comments about the client and the campaign, and more importantly, the master script itself. While the structure of the master script cannot be formally modified, agents are encouraged to personalize the wording of sections, especially the pitch, while preserving key points. This modification is done either in hand annotations or orally.

Most new agents start off on an engagement campaign. Engagement scripts are good for beginners as they are brief and their language is not technical. Once campaign managers deem them capable, agents are trained for high-end campaigns, referred to as the consultative. Before explaining what personalization and consultation refer to, I consider how these strategies are monitored by management.

Figure 1 The script as a skeleton or scaffolding

\begin{tabular}{|c|c|c|c|c|}
\hline $\begin{array}{l}\text { Greeting to Receptionist } \\
\text { Good moming / afternoon this is }<\text { TM name } \\
\text { calling on behalf of BIS. } \\
\text { May I speak with < It contact's name> } \\
\text { Or someone within your IT dept if no contact } \\
\text { supplied. }\end{array}$ & \multicolumn{2}{|c|}{$\begin{array}{l}\text { YES - Go to Q1 } \\
\text { WHAT IS IT IN REGARDS TO? - Go to } \\
\text { Objection Handling \#1 }\end{array}$} & \multicolumn{2}{|l|}{$\begin{array}{l}\text { Objection Handling } \# 1 \text { : } \\
\text { A complimentary Email Threats report, it should only } \\
\text { take a few minutes } \\
\text { YES - continue } \\
\text { NO - thank you anyway. }\end{array}$} \\
\hline \multicolumn{2}{|c|}{$\begin{array}{l}\text { Good moming/afternoon this is CTM name> calling on behalf } \\
\text { of BIS. } \\
\text { Can I confirm you are involved in the IT at company name> } \\
\text { No - ask to be transferred to the correct contact } \\
\text { YES - continue }\end{array}$} & \multicolumn{3}{|c|}{$\begin{array}{l}\text { The Introduction of the Client } \\
\text { Can I confirm that you are familiar with BIS? } \\
\text { YES-Go to Pitch } \\
\text { NO- }\end{array}$} \\
\hline \multicolumn{5}{|c|}{$\begin{array}{l}\text { Pitch: } \\
\text { The reason for my call today is that BIS has put together a complimentary report on SBP (Safe Browsing Policy). The SBP is the bedrock of any } \\
\text { organisation's management of employee use of corporate IT systems. This whitepaper is written by an extemal company that looks at the legal } \\
\text { implications of making sure your SBP is solid. By reading this whitepaper you will leam about: }\end{array}$} \\
\hline \multicolumn{5}{|c|}{$\begin{array}{l}\text { Other } \Pi \text { personnel have received it and found it to be very useful. Can I send you the whitepaper it is completely complimentary? } \\
\text { (Objection handling: We do not send any spam or give your email out to third-parties.) }\end{array}$} \\
\hline \multicolumn{4}{|c|}{$\begin{array}{l}\text { Yes- Great I just need to get a few details to be able to send it through to you } \\
\text { No- Thank you for your time today (not interested) }\end{array}$} & \\
\hline 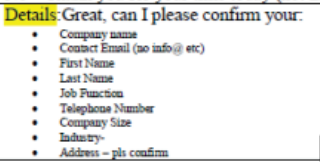 & $\begin{array}{l}\text { Closing } \\
\text { Thank yc } \\
\text { represen }\end{array}$ & $\begin{array}{l}\text { a for your time today. You will sho } \\
\text { tative from BIS will contact you }\end{array}$ & $\begin{array}{l}\text { y receive the whitepaper via email and a } \\
\text { hin the next couple of weeks. Thank you. }\end{array}$ & \\
\hline
\end{tabular}


There are two types of monitoring: qualitative and quantitative. Quantitative monitoring measures how many calls agents make and how many leads they obtain. For the hypothetical script below, team leaders and call center managers know that a call containing a lead should last around three minutes. They compare agents' calls to those statistics. If a call falls short, they assume technique is at fault.

In order to do qualitative monitoring, team leaders listen to calls in order to make sure the structure of a script is adhered to, covering each of the following sections: (1) introduction to the gatekeeper, (2) handling potential objections, (3) objection handling (continued), (4) introducing themselves to the contact, (5) introduction of the client, (6) the pitch, (7) confirming the details, (8) and ending the call.

The key sections of the scripts are: 'the pitch' and 'introduction of the client', the external company that hired the call center to conduct a campaign. This information is vital and must be mentioned during a call. A call center monitor listens to determine whether an agent mentions all sections and key points.

Imagining the master script as a skeleton makes it possible to claim that agents' calls can be monitored even if they are speaking another language. Former team leader Olivia explains:

\section{Extract 5}

I used to monitor agents in a lot of languages which I don't speak or understand [...] but I could always tell from their intonation whether they follow the script. (Olivia, former team leader)

It is important for agents to both follow the script outline and to personalize it. Success or failure is based on a set of interactive competencies, such as personalization, not on rote performances. Agents need to learn how to utilize a script and interact with an interlocutor in order to make it seem as though they are authoring the text. These skills are introduced during training but require practical experience to develop. During initial training, team leaders share personal strategies for how to personalize a script. Important as they are, agents do not receive special incentive for pursing these strategies as they are 'hidden' oral skills unrecorded by the software. 


\section{Learning personalization}

Elsa and Jeremy, two team leaders, explain what personalization means to them. For Elsa,

\section{Extract 6}

It's not about changing the script, I think it's more about using the key elements in the script and making it sound like you [...] I rewrite it [the pitch]. I mean the scripts are good but they sound like someone else, $[\ldots]$ whatever you write down, just make it sound like you're interested. (Elsa, team leader)

When it comes to training the agents, team leaders advise them to make their hand-written changes to the pitch prior to calling. After a few calls and feedback, additional hand-written notes are added and as a result, agents' personal versions are likely to be unique. The majority of agents stress that none of their modifications affect a script's main content (the skeleton or scaffolding). As Jack explains:

\section{Extract 7}

We can't change the content of the script $[\ldots]$ But we can change how we communicate the content... the style, the expression... that sort of thing; (Jack, agent)

For his part, Hugo stresses that one must be selective:

\section{Extract 8}

The script is like the tiny [training] wheels on a bicycle [...] you need to know when to let it go. [...] it's even like a love letter. If you read a love letter to someone, it sounds silly, so you need to maybe read a little bit, take part of them, and then make a speech about that [...]. I think scripts are good because it gives you like a base [...]. (Hugo, agent) (Source: Woydack 2019)

Similar to jazz musicians who "extemporize new melodies" (Johnson-Laird 2002, 416), agents improvise within the script outline. When asked how they succeed in personalizing while adhering to the outline and content of the script, callers cite three factors: i) performance-driven adaptation, ii) responsiveness, and iii) self-presentation.

Performance-driven adaptation: Several agents point out that they listen to and copy successful coworkers and that this may lead to changes of their version(s). Nevertheless, although agent Jackie told me that she mimics others, she still claims to do it "her way".

Team leaders also like to place new agents next to experienced ones calling in the same language. Again, agents mention asking high achievers for their script. 
Sometimes, during the course of a campaign, there are debriefings when feedback is given about what works and what does not.

Responsiveness: Most callers state that the other person's reaction guides deviations from the script. Agent Oliver confirms this:

Extract 9

Obviously conversations don't always follow the script [...] so we need some sort of leniency and flexibility in the script ... if this one person says this, I need to react differently and say something different. (Oliver, agent)

Personalization of the calling scripts entails projecting a certain image and building rapport with the other person. Agent Kate explains:

Extract 10

I think you have to mirror the other person you are talking to. You can't be super bubbly when they are quiet $[\ldots]$ You also want them to like you $[\ldots]$ you should be like their friend and colleague and talk to them that way. (Kate, agent)

Kate adds that 'mirroring' is not only a way to convey to the other person that one is an individual, but also a means to accommodate him/her and to be empathetic.

Agents (who are not always fluent) must be properly prepared to diffuse any possible objections or hostility they may encounter on the phone. During training, agents are armed with 'self-defense' strategies that include politeness formulas, pre-determined sets of phrases and expressions they selectively adapt to complement a script.

Team leaders and campaign floor managers encourage and rely on agents adopting strategies to make them more responsive and successful. These examples show how agents learn to interact with their calling script and stop seeing it as static but instead as a guide from which they improvise (see Woydack 2019).

Self-representation: Besides projecting themselves as friendly, empathetic, good listeners, poetic and funny, agents say they draw on and take advantage of language ideologies and stereotypes to portray a degree of authenticity. One of these is the perceived superiority of English and of London, as birthplace and guardian of this global language ${ }^{3}$. As Antonio, who often calls in English to foreign countries, explains:

3 In other countries, the opposite might be the case and calling in English is avoided at all costs. 


\section{Extract 11}

People in South African or some Asian countries like receiving calls in English

$[\ldots]$ it impresses them if you say you are calling from London [... they think you must be important and you are sophisticated. [...]. (Antonio, current agent)

Others stress the need to attend to cultural knowledge of specific countries/ regions. Merely speaking the same language does not mean having the same culture. In the call center, teams may be formed based on languages rather than countries. Other callers assert that adding country-specific jokes to the script helps.

Accents can help portray a sense of authenticity and help agents reach their targets. Agents try to sound 'authentic' to demonstrate that they are really locals. They do this in a variety of ways. They might adopt a local dialect or a posh accent (Woydack 2019).

Harry asserts that British people like being called by someone who sounds British.

\section{Extract 12}

I think British people like being called by someone that sounds very British; you want that authenticity* (Harry, agent)

Corporate management is concerned with quantity, that is, agents reaching a daily target so they can make a profit. This can be evaluated through reviews of the software-maintained records. Conversely, the call center management on the floor is also interested in call quality and so monitors and assesses how well agents interact with the scripts and present themselves. This may involve listening in to calls. If agents leave out key parts of a script, they may be fired, but this is assessed in the context of call results. With the exception of high pressure times when numerical targets must be met, personalization is considered by floor managers to be a competence that can be measured and improved.

\section{Learning the consultative approach}

Similar to the personalization strategy, using the consultative approach requires more skills than simply reading from a script verbatim. Only agents who are considered good at personalization and fluent in the language of a target market are trained in the consultative method. This strategy is reserved for high-end campaigns, where scripts are long, contain a great deal of information, and include many questions.

Whereas personalization focuses on agents' individual preferences and needs and mostly entails interacting with the script and presentation of the self, the 
consultative approach is conversational. Jeremy, who is considered the expert in the call center on consultative calling, describes it the following way:

\section{Extract 13}

The consultative approach $[\ldots]$ is far more about them than it is about us. I find with engagement [scripts] it's all about us really. The consultative approach $[\ldots]$ is like, 'What problems have you got at the moment? What issues are you having?' [...] we need guys that can sit on the phone for [...] 20 minutes. It's going to be far more knowledge based, for the agent. [...]. It's [...] far more [...] having a conversation. (Jeremy, team leader) (Source: Woydack 2019)

Using this method, the agent is free to integrate questions into the eight sections of the already personalized master script or to introduce issues after the script's basic elements have been covered. Jeremy asserts that there are three different components of every call: the tone, flow, and content of the conversation.

\section{Extract 14}

Regardless of what the information is, it has to be put in an engaging way+ [...] I'll change sentences, and I'll lynchpin it around the information that matters. I'll never do the same every time. [...]. I just mirror really, that's what I tend to do [...] You should always dictate where it [the conversation] is going but let them dictate the tone...." (Jeremy, team leader) (Source: Woydack 2019)

For an agent to respond to the tone and flow, listening is critical. Extract 15

Listening is so important and it's the key skill. We have to listen not just to what they're saying but how $[\ldots]$. Those are all the cues we have. (Elsa, team leader)

Team leader Abby agrees:

Extract 16

When you call using the consultative approach you need to be a very good listener to be honest [...] it's all about listening for the information, things, that might be useful for the client $[\ldots]$ pointers and so on $[\ldots]$ information you can add to your remarks [...], that's why they [the client] need [agents making calls]. (Abby, team leader)

Jeremy's and Abby's comments suggest that agents learn global and selective listening as part of working on the phone. Agents also need to take notes while on the phone. These notes are supposed to summarize what the other person said, so-called 'lead remarks' and any keywords mentioned by them. Notes can then be analyzed by campaign managers and subsequently passed on to the client. There is pressure to produce quality notes to justify for the client the high costs involved. 
Only agents working on high-end campaigns are trained in this approach. On the whole, the strategy is designed to teach how to focus a conversation on the other person rather than focus on a script. The ideal performance occurs when one believes agents are speaking freely - that is not using a script.

The success of these strategies, including the consultative approach, should be evident from information that agents summarize in reporting their conversation. If something indicates that their strategy is not working, the call monitor downstairs investigates. Continued failure results in agents getting fired.

To summarize, agents are aware of the need to manage the reactions of the people they talk to and their own conversational style. They must adapt their tone of voice and register to their interlocutor. In face-to-face communication, one deduces much from body language. Agents do not have these visual cues on the phone. Consultation skills take time to develop and are not innate. Corporate management desires agents to follow a script verbatim. The linguistic practices on the ground show that lower level call floor management and agents do not do this but rather are trained to work with a script. Agents, call center managers, and team leaders personalize and improvise scripts. The system is thus marked by contradiction as although team leaders and call center managers value the quality that approaches such as personalization bring about and argue that it leads to agents meeting a higher numerical target, the oral work that agents put into calling is not textualized by the system and thus not officially acknowledged and not remunerated as such although team leaders and call center managers are aware of it. It remains invisible to corporate managers upstairs who do not listen into calls and only access call statistics. Call floor managers do not want improvisatory practices recorded by the software and visible to the corporate management as this would make obvious the practices that defy the guidelines they receive from upstairs. Instead, they mediate the tension that the quality and quantity demands create at CallCity. Call floor managers would like to change the bonus system and the appraisal of employees to include quality instead of just quantity, but corporate management is satisfied with their presumptions about practice and their ability to accommodate high attrition.

\section{Conclusion}

I started by drawing on ethnographic data to challenge the fluency assumption about language work within multilingual call centers and to revise the notion that call center work is exclusively language work. I also countered negative assumptions about the low level of skills required for call center work. 
In response to my three questions I summarize the following. The recruitment process centers on supply and demand. Call centers recruit from a variety of sources, including language agencies. For languages in high demand, fluency of agents is often a secondary consideration. Regarding the question of training, agents learn to work with scripts on the job. They are taught script fluency and interaction with scripts through two strategies. The first one is personalization to help new agents become comfortable with a scripted text and present themselves through that outline. The second one is for advanced agents and aims to teach them how to focus conversation on the other person rather than on the script. Regarding the question of performance, we have seen that 'nativeness' is often used as a synonym for 'fluency' and that neither is a good predictor of success Ultimately, however, call centers are for-profit businesses more concerned with each agent reaching a given target than with individual levels of fluency.

More generally, I have shown that agents acquire new skills and expertise by working at a call center. Parts of these new competencies include 'script fluency' and often improved fluency in the language in which they make calls. I also showed that although agents' abilities to follow scripts are measured, 'script fluency' is not easily captured and must be acquired over time. Agents learn and become versed in improvising around a script. In fact, agents themselves might not value this skill at first and doubt its usefulness as they receive no immediate monetary award for it. But, as I have shown elsewhere (Woydack n.d.), it can be argued that this skill is in fact, impression management, a skill transferable to other jobs. Moreover, contrary to popular belief, my study shows that agents are often not fluent but rather beginner or lower-intermediate level in the language in which they call.

There is similarity in my work with the motivational cultural intelligence competence described by Presbitero (2017). He argues in a quantitative study of call center performance in the Philippines that it is not just language ability that contributes to the success of agents in call centers, but also their "persistence and tenacity to continue on with the challenging work of attending to the needs and wants of the multicultural clients and customers in the call center context" (2017, 1549 ) in the absence of visual cues. I have described this as well and addressed how agents socialize into acquiring this competence.

How does this paper compare with the other bilingual studies presented previously? There is some overlap with Alarcón \& Heyman's study. The call centers they studied in El Paso, Texas were permissive of accents, as was a call center in London. They also found that El Paso agents were not always fluent in the language they took calls in, like their London counterparts. There are 
similarities when it comes to the use of scripts. In general, Alarcón and Heyman found that the easy, standardized campaigns are script-based, but campaigns become less script-focused at higher levels. I found the same to be true in London. Similarly, Alarcón and Heyman found management in the El Paso call center struggling to assess agents' linguistic ability. The authors make note of the fact that linguistic training for agents does not exist $(2013,17)$ and that agents' Spanish is not properly assessed. Those findings are similar to the call center case study presented here.

An important difference between our findings is that Alarcón and Heyman (2013) argue that "bilingualism is used in the labor market as a sign of cheap and flexible labor, rather than as economically and socially valued skill" (2013, 1). My study found that agents in London use scripts to improve their language skills which in many cases led to them successfully finding better remunerated employment outside the call center industry, demonstrating that call centers can function as language training opportunities. Similarly, in a survey of Canadian call centers, Buchanan and Koch-Schulte (2000) observe that newly arrived immigrants to Canada often work in call centers in Toronto to improve their English before moving on to other jobs. Thus it can be said that bilingual/ multilingual call centers are not always dead end career-killers as suggested, but that educational levels and call center learning may scaffold career trajectories.

Finally, I have shown that it is incorrect to conclude that agents only need language to be successful; rather, they need a particular kind of 'script fluency' to succeed. They need to employ personalization and consultation. As Cameron (2000a, 116) notes, people will often be ruder on the phone than they would ever be in person, and successful agents learn techniques to overcome such challenges. I argued that calling agents 'language workers' obscures what their work actually entails, which skills they have, and what is involved in being a successful call center worker. I believe 'interactive professional' better describes what they do because it focuses on the dialogic features of their requisite calling tasks.

By focusing on a call center where fluency is not a prerequisite, this study refutes the notion that call center work is just 'language work'. On first sight, call center work may appear low-skilled but in fact, by looking beyond common assumptions, calling scripts help agents reach fluency and are a tool for developing new skills given time, training, and experience. By homing in on the variety of skills (many of them invisible) required for call center work I aim to remove the stigma that surrounds call centers (cf. Woydack 2017). As I have argued elsewhere (Woydack, n.d.), the invisible skills needed for the call center work described here means that such work can be described as knowledge work. 


\section{References}

Alarcón, Amado, and Josiah McC. Heyman. 2013."Bilingual Call Centers at the US-Mexico Border: Location and Linguistic Markers of Exploitability" Language in Society 42 (01): 1-21.

Batt, Rosemary, and Lisa Moyninan. 2002."The Viability of Alternative Call Centre Production Models." Human Resource Management Journal 12 (4): 14-34.

Brock, David. 2013. Social Class in Applied Linguistics. London: Routledge.

Boutet, Josiane. 2012. "Language Workers. Emblematic Figures of Late Capitalism." In Language in Late Capitalism: Pride and Profit, edited by Alexandre Duchêne and Monica Heller, 207-29. New York/London: Routledge.

Buchanan, Ruth Margaret, and Sarah Косн-Schulte. 2000. Gender on the Line: Technology, Restructuring and the Reorganization of Work in the Call Centre Industry. Policy Research / Status of Women Canada. Ottawa: Status of Women Canada.

Cameron, Deborah. 2000a. Good to Talk? London: SAGE Publications.

-.2000b. "Styling the Worker: Gender and the Commodification of Language in the Globalized Service Economy." Journal of Sociolinguistics 4 (3): 323-47.

—. 2008. "Talk from the Top Down." Language E Communication 28 (2): 14355.

Coulmas, Florian. 1981. A Festschrift for Native Speaker. The Hague: Mouton Publishers.

DTI. 2004. "The UK Contact Centre Industry: A Study" London: Department of Trade and Industry.

Duchêne, Alexandre. 2009. "Marketing, Management and Performance: Multilingualism as Commodity in a Tourism Call Centre." Language Policy $8(1): 27-50$.

Duchêne, Alexandre, and Monica Heller, eds. 2012. Language in Late Capitalism: Pride and Profit. Routledge Critical Studies in Multilingualism. New York: Routledge.

Fraurud, Kari, and Sally Boyd. 2011. "The Native-Non-Native Speaker Distinction and the Diversity of Linguistic Profiles of Young People in Multilingual Urban Contexts in Sweden." In Young Urban Swedish: Variation and Change in Multilingual Settings, edited by Roger Källström and Inger Lindberg, 1:67-87. Göteborg: Göteborgs universitet. 
Frenkel, Stephen, ed. 1999. On the Front Line: Organization of Work in the Information Economy. Cornell International and Labor Relations Report, no. 35. Ithaca, N.Y: ILR Press.

Hampson, Ian, and Anne Junor. 2005. "Invisible Work, Invisible Skills: Interactive Customer Service as Articulation Work." New Technology, Work and Employment 20 (2): 166-81.

Heller, Monica. 2003. "Globalization, the New Economy, and the Commodification of Language and Identity. Journal of Sociolinguistics 7 (4): 473-92.

—. 2010. "The Commodification of Language." Annual Review of Anthropology 39 (1): 101-14.

Heller, Monica, and Lindsay Bell. 2012. "Frontiers and Frenchness: Pride and Profit in the Production of Canada." In Language in Late Capitalism: Pride and Profit, edited by Alexandre Duchêne and Monica Heller, 161-83. New York/London: Routledge.

Houlihan, Maeve. 2002. "Tensions and Variations in Call Centre Management

Strategies." Human Resource Management Journal 12 (4): 67-85.

Johnson-Laird, Philip N. 2002. "How Jazz Musicians Improvise." Music Perception 19 (3): 415-42.

Korczynski, Marek. 2001. "The Contradictions of Service Work: The Call

Centre as a Consumer Oriented Bureaucracy." In Customer Service - Control, Colonisation and Contradiction, edited by A Sturdy, I Grugilis, and H Wilmott, 79-101. London: Macmillan.

Lindsay, Colin, and Ronald W. McQuaid. 2004. "Avoiding the 'Mcjobs': Unemployed Job Seekers and Attitudes to Service Work." Work, Employment and Society 18(2):297-319. https://doi.org/10.1177/09500172004042771. Lockwood, Jane. 2012. "Are We Getting the Right People for the Job? A Study of English Language Recruitment Assessment Practices in the Business Processing Outsourcing Sectorः India and the Philippines." Journal of Business Communication 49 (2): 107-27.

McGill, Kenneth. 2013. "Political Economy and Language: A Review of Some Recent Literature: Political Economy and Language." Journal of Linguistic Anthropology 23 (2): E84-101.

Mirchandani, Kiran. 2004. "Practices of Global Capital: Gaps, Cracks and Ironies in Transnational Call Centres in India." Global Networks 4 (4): 35573.

- 2012. Phone Clones: Authenticity Work in the Transnational Service Economy. Ithaca: ILR Press. 
Muller, Michael J. 1999. "Invisible Work of Telephone Operators: An Ethnocritical Analysis." Computer Supported Cooperative Work (CSCW) 8 $(1-2): 31-61$.

Pennycook, Alastair. 1994. The Cultural Politics of English as an International Language. Language in Social Life Series. London; New York: Longman.

Presbitero, Alfred. 2017. "It's Not All about Language Ability: Motivational Cultural Intelligence Matters in Call Center Performance." The International Journal of Human Resource Management 28 (11): 1547-62.

Richardson, Ranald, and Vicki Belt. 2001."Saved by the Bell? Call Centres and Economic Development in Less Favoured Regions." Economic and Industrial Democracy 22 (1): 67-98. https://doi.org/10.1177/0143831X01221004.

Ritzer, George. 1998. The McDonaldization Thesis: Explorations and Extensions. London; Thousand Oaks, Calif: SAGE Publications.

Roy, Sylvie. 2003."Bilingualism and Standardization in a Canadian Call Center: Challenges for a Linguistic Minority Community." In Language Socialization in Multilingual Societies, edited by Robert Bayley and Sandra Schecter, 26987. Clevedon: Multilingual Matters.

Russell, Bob. 2004. "Are All Call Centres The Same?" Labour E Industry: A Journal of the Social and Economic Relations of Work 14 (3): 91-109.

- 2008. "Call Centres: A Decade of Research." International Journal of Management Reviews 10 (3): 195-219.

Sallaz, Jeffrey J. 2015. "Permanent Pedagogy: How Post-Fordist Firms Generate Effort but Not Consent." Work and Occupations 42 (1): 3-34.

Spolsky, Bernard. 2009. Language Management. Cambridge; New York: Cambridge University Press.

TAYlor, Phil, and Peter Bain. 1999. "An Assembly Line in the Head': Work and Employee Relations in the Call Centre." Industrial Relations Journal 30 (2): 101-17.

—. 2004. "Call Centre Offshoring To India: The Revenge of History?" Labour E Industry: A Journal of the Social and Economic Relations of Work 14 (3): 15-38. TAYlor, Philip, and Peter Bain. 2001."Trade Unions, Workers'Rights and the Frontier of Control in UK Call Centres." Economic and Industrial Democracy $22(1): 39-66$.

Woolard, Kathryn Ann. 1998. "Introduction: Language Ideology as a Field of Enquiry." In Language Ideologies: Practice and Theory, edited by Bambi B. Schieffelin, Kathryn A. Woolard, and Paul V. Kroskrity, 3-47. Oxford, New York: Oxford University Press. 
Woydack, Johanna. forthcoming. “Call Center Agents' Skills: Invisible, Illegible, and Misunderstood," forthcoming.

—. 2016. "Superdiversity and a London Multilingual Call Centre." In Engaging Superdiversity: Recombining Spaces, Times and Language Practices, edited by Karel Arnaut, Martha Sif Karrebaek, Massimiliano Spotti, and Jan Blommaert, 220-51.7. Bristol: Multilingual Matters.

- 2017. "Call Center Agents and the Experience of Stigma." Working Papers in Urban Language Literacies. King's College London. <https://www.academia. edu/33711030/WP215_Woydack_2017._Call_center_agents_and_the_ experience_of_stigma $>$.

-. 2019. Linguistic Ethnography of a Multilingual Call Center: London Calling. Cham: Springer International Publishing.

—. n.d. "Impression Management Games: Language and Mobility among Sothern European Migrants in a London Call Center."

Woydack, Johanna, and Ben Rampton. 2016. "Text Trajectories in a Multilingual Call Centre: The Linguistic Ethnography of a Calling Script." Language in Society 45 (05): 709-32. 